\title{
HIGH-SENSITIVITY RADIOCARBON DATING IN THE 50,000 TO 70,000 BP RANGE WITHOUT ISOTOPIC ENRICHMENT
}

\author{
AUSTIN LONG and ROBERT M. KALIN ${ }^{1}$ \\ Environmental Radioisotope Center, Department of Geosciences, The University of Arizona \\ Tucson, Arizona 85721 USA
}

\begin{abstract}
Calculations show the possibility of detecting ${ }^{14} \mathrm{C}$ remaining after 10 or 11 decay half-lives in natural materials, such as wood, using commercially available liquid scintillation (LS) detectors. Assuming in-situ ${ }^{14} \mathrm{C}$ production has contributed insignificantly to the measured ${ }^{14} \mathrm{C}$, one can calculate finite ages approaching $70 \mathrm{ka}$. In practice, defensible finite age determinations involve careful considerations of several critical elements in the procedure. These critical elements are: 1) the integrity of the sample itself, in terms of younger contaminants and of in situ-produced ${ }^{14} \mathrm{C}$; 2) the availability of "dead" background material; 3) chemical blank in laboratory preparation of, in this case, benzene; and 4) stability of background and efficiency of the LS counting system. High-sensitivity ${ }^{14} \mathrm{C}$ dating reveals a low level of memory effect ${ }^{14} \mathrm{C}$ in benzene synthesized in the laboratory from anthracite or marble. This level of ${ }^{14} \mathrm{C}$ activity is equivalent to that found in $53 \mathrm{ka}$ old wood, and thus, is not distinguishable from petrochemical benzene used in routine dating. If careful control of laboratory conditions can maintain this ${ }^{14} \mathrm{C}$ blank constant, reproducible dating beyond $53 \mathrm{ka}$ would be possible. Although we have not completed a systematic analysis of the origins of memory effect, lithium reactors used in acetylene production and organic solvents in wood pretreatment are likely sources.
\end{abstract}

\section{INTRODUCTION}

The specific activity of modern (pre-industrial) ${ }^{14} \mathrm{C}$ after 11 half-lives $(11 \times 5730=63,030 \mathrm{yr})$ of decay is 0.00662 disintegrations per minute $(\mathrm{dpm})$ per gram of carbon. By convention (Stuiver \& Polach 1977), a sample must have a count rate $>2$ o above background, to have a finite age assigned to it. To measure such low levels of ${ }^{14} \mathrm{C}$ activity, a ${ }^{14} \mathrm{C}$ dating system must have a low and steady background to minimize the statistical uncertainty in the background, and the sample under examination must have as much carbon as is practical to minimize the statistical uncertainty in the sample count rate. Unfortunately, counter backgrounds and sample size are positively correlated (Stuiver, Robinson \& Yang 1979). Longer counting times improve the statistical resolution of lowcount-rate samples, but the longer the counting time, the greater the probability of electronic shifts in background or efficiency. Approaches to this problem include: 1) development of special counters with extremely high active volumes and/or very low backgrounds (Oeschger \& Wahlen 1975; Povinec 1992); 2) the use of isotopic enrichment to concentrate the ${ }^{14} \mathrm{C}$ into normal volume gas proportional counters; and 3) the use of large volume ( $>10 \mathrm{~g}$ of carbon), high-stability, lowbackground liquid scintillation counting (LSC) systems. The high density of carbon and low cosmic-ray profile in a vial of benzene potentially give a high sample-to-background count-rate ratio. Recent developments in LSC technology take advantage of these attributes of benzene for high-sensitivity ${ }^{14} \mathrm{C}$ dating.

The only finite ${ }^{14} \mathrm{C}$ dates in the $60-70$ ka range now available were obtained by $\mathrm{CO}_{2}$ gas proportional counting after isotopic enrichment by thermal diffusion (Grootes et al. 1975; Grootes 1977, 1978; Grootes et al. 1980). This method works well and has produced numerous finite range dates up to about $75 \mathrm{ka} \mathrm{BP}$. Its disadvantages are that it requires over $100 \mathrm{~g}$ of carbon and the use of an elaborate ca. 4-m-tall column and bulb apparatus for 45 days. LSC also has the potential of detecting low levels of ${ }^{14} \mathrm{C}$ (Gupta \& Polach 1985; Polach 1987). The purpose of this study is to

${ }^{1}$ Present address: Center for Applied Isotope Studies, The University of Georgia, 120 Riverbend Road, Athens, Georgia 30605 USA 
investigate the detection limits of ${ }^{14} \mathrm{C}$ (high-sensitivity ${ }^{14} \mathrm{C}$ dating) in real samples using the latest LSC measurement technology, and to evaluate different chemical phases for minimizing contamination with younger carbon. Here we report on our recent investigations into the ${ }^{14} \mathrm{C}$ detection limits of the entire LSC system, including all chemical and physical steps in the process. To illustrate, we tested a wood specimen from Alaska, whose expected age was $125 \mathrm{ka}$ BP. Our radiometric analysis yielded ${ }^{14} \mathrm{C}$ at the $50 \mathrm{ka}$ level. Whether this is the correct age, an artifact of the chemical pretreatment procedure, or of in-situ production is uncertain.

\section{METHODS}

The LSC technique employed in this study requires the laboratory synthesis of benzene, with all six benzene carbon atoms derived from the sample. See Noakes et al. (1963) for details of the basic benzene synthesis procedure. Wood and anthracite coal samples were processed in this study; samples were combusted to $\mathrm{CO}_{2}$, which then reacted with hot lithium to form $\mathrm{Li}_{2} \mathrm{C}_{2}$. Addition of tritium-free water to the cooled lithium carbide produced acetylene; then the acetylene was catalytically $\left(\mathrm{Cr}_{2} \mathrm{O}_{5} / \mathrm{Al}_{2} \mathrm{O}_{3}\right)$ trimerized to benzene. A scintillant compound (butyl-PBD) was dissolved in the benzene, and the benzene counted for $12 \mathrm{kmin}$. Each benzene sample in the present study contained $11.5 \mathrm{~g}$ of carbon. Routine counting in this laboratory employs up to $2.6 \mathrm{~g}$ of carbon counted for $2 \mathrm{k}$ min.

In addition to increasing the sample size and counting time for this study, it was necessary to consider all suspected contributors to ${ }^{14} \mathrm{C}$ in the sample which were not radioactive decay remnants of the original ${ }^{14} \mathrm{C}$ incorporated in the growing tree. Possible sources of extraneous ${ }^{14} \mathrm{C}$ are: 1 ) environmental carbon while wood was in situ; 2) carbon in sample pretreatment reagents; and 3) carbon in benzene synthesis reagents and apparatus (system memory effects). Sources 2 and 3 are often called chemical blanks. In addition, all $\beta$-counting systems have a counter background, which is the minimum count rate of a sample containing no ${ }^{14} \mathrm{C}$. Only 1 part of modern carbon contaminant per 2000 parts of "infinitely old" carbon will produce an apparent ${ }^{14} \mathrm{C}$ age of $63 \mathrm{ka}$. Therefore, both counter background and chemical blank must be minimized, and their values and variabilities must be well known and statistically well behaved. Kalin and Long (1989) previously discussed counter background; we discuss below the measures taken in this study to minimize environmental contamination and chemical blank for dating old wood.

In this study, a white spruce wood (Picea glauca) sample, collected in 1987, was provided by Dr. Troy Péwé of Arizona State University. The sample (Péwé No. 187) was taken from the Eva Creek Forest Bed at its type locality, $16 \mathrm{~km}$ west of Fairbanks, Alaska. Figure 1 shows the geological section from which the specimen was taken. We chose this sample as a geological blank because it is believed to have grown during the last interglacial, ca. 125 ka ago (Péwé 1975, written communication 1991; Westgate 1988). This wood specimen is well preserved, because it was overlain by $15 \mathrm{~m}$ of permafrost soil until recent mining trenching. The specimen was not rooted in place.

Laboratory processing included first an inspection to identify portions with no visible degeneration, and then sampling only the firmest and freshest-appearing portions. For cellulose preparation, $300 \mathrm{~g}$ of selected wood were ground to sawdust size for extraction of waxes and resins by ultrasound, with a mixture of $67 \%$ toluene and $33 \%$ ethanol. The wood was then ultrasonically washed again in ethanol, and then extracted in a Soxhlet apparatus with ethanol. LSC of the toluene indicated no counts in the ${ }^{14} \mathrm{C}$ spectrum. The scintillation spectrum from the ethanol indicated that it derived from fermentation of modern plants. After Soxhlet extraction, the sample was oven dried, and the remaining solvent was removed by boiling in water and oven drying. The boiling step was designed to remove possible extraneous mobile sugars and laboratory solvents used in pretreatment, 


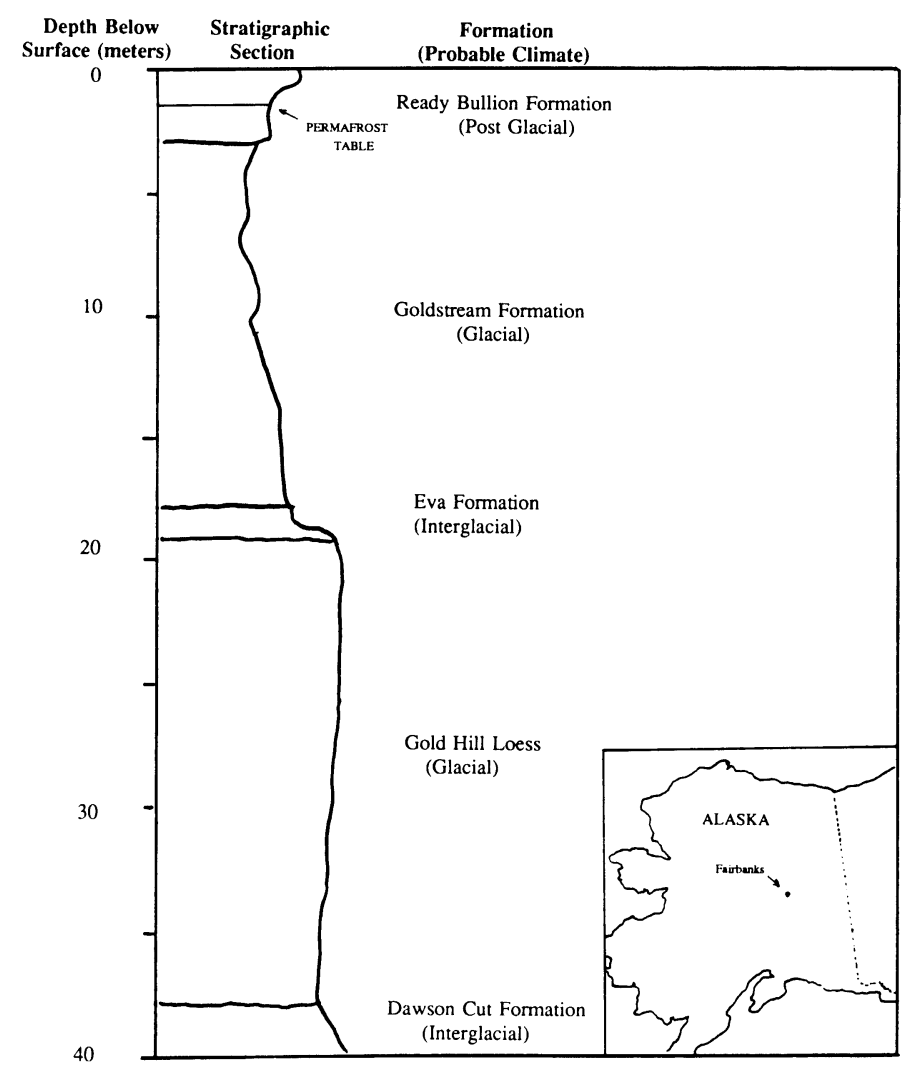

Fig. 1. Stratigraphic section from the Eva Creek locality (redrawn from Péwé (1975))

such as alcohol, which are more volatile than water. The bleaching step involved sodium hypochlorite solution acidified with phosphoric acid, and heated to $90^{\circ} \mathrm{C}$ until the wood was light tan (first of two runs) or paper white (second run), indicating removal of lignin.

In the combustion procedure, oxygen was passed through a Vycor glass tube containing a sample heated by gas-burner flames. Standard purity tank-gas oxygen may contain traces of atmospheric $\mathrm{CO}_{2}$ (Grootes et al. 1975). We passed the oxygen through a tube filled with Ascarite ${ }^{\mathrm{TM}}$ to remove $\mathrm{CO}_{2}$ before entering the combustion tube. The carbon collected in our Ascarite filter was measured at about $36 \mathrm{pMC}$. To minimize memory effects from previous samples, the entire system is thoroughly cleaned between samples. This is routine and effective in normal processing, but insufficient for high-sensitivity ${ }^{14} \mathrm{C}$ dating. As we illustrate below, it is necessary to dedicate combustion-lithium-catalysis lines to high-sensitivity dating, and to purge these lines by combusting ${ }^{14} \mathrm{C}$-free samples before processing samples to be dated.

After combustion, the $\mathrm{CO}_{2}$ is reacted with lithium at about $600^{\circ} \mathrm{C}$ to form $\mathrm{Li}_{2} \mathrm{C}_{2}$. Any contaminant carbon in the lithium will also react to $\mathrm{Li}_{2} \mathrm{C}_{2}$ at this time. Each purchase of lithium is from a batch selected for highest purity and lowest carbon content. Exposure to air during loading of the lithium reactor, though minimized as much as possible, inevitably exposes lithium pellet surfaces to atmospheric $\mathrm{CO}_{2}$, possibly adding to the sample blank. Our records show, however, no difference in sample blank, for routine samples, between the first lithium from a freshly-opened can to the last lithium in the can. In these high-sensitivity tests, we used the same fresh batch of lithium for all samples. Previous experiments (Radnell \& Muller 1980) demonstrated that the stainless steel lithium reactor can be a source of ${ }^{14} \mathrm{C}$ memory effects. Routine mechanical and chemical cleaning 
cannot eliminate all memory of previous high-activity samples. It is assumed that carburization and decarburization of steel, possibly in micropores in the reactor inner surface, is responsible for this effect (Radnell \& Muller 1980).

The next step is the hydrolysis of lithium carbide with pure, tritium-free water to produce acetylene. The acetylene is then trimerized to benzene by adsorption onto a catalyst of $\mathrm{Cr}_{2} \mathrm{O}_{5}$ on $\mathrm{Al}_{2} \mathrm{O}_{3}$ pellets starting at $25^{\circ} \mathrm{C}$, but this exothermic reaction can raise the reaction temperature to about $50^{\circ} \mathrm{C}$. We used the identical catalyst for the series of anthracite purges and for the test sample.

The two independent determinations of the Eva Creek sample were separated by several months, and each was preceded by two (first run) or four (second run) anthracite samples processed through the same lines, using the same catalysts. Anthracite is considered to have undetectable levels of ${ }^{14} \mathrm{C}$. The purpose of the anthracite runs was to purge the lines and catalysts of any ${ }^{14} \mathrm{C}$ memory of the previous standard runs. Each sample run produced over $12 \mathrm{~g}$ of benzene. All samples, anthracites, wood specimens and modern standards were counted for $12 \mathrm{kmin}$ in a Quantulus (LKB-Wallac) LS detector; the detector is located in a temperature- and humidity-controlled underground counting room, with $10 \mathrm{~m}$ of concrete and soil overburden. The Quantulus stores the energy spectra of the cumulative counts, and allows energy discrimination. Count rates were recorded every $50 \mathrm{~min}$ for statistical analysis. See Kalin and Long (1989) for more complete description of the counting system.

\section{RESULTS}

The Quantulus LS counters are set to minimize the effect of spectral shifts on ${ }^{14} \mathrm{C}$ detection efficiency (described in McCormac 1992). The present configuration detects $71.723 \%$ of the ${ }^{14} \mathrm{C}$ disintegrations in the benzene. Table 1 shows standard and background count rates (and $\delta^{13} \mathrm{C}$ data)

TABLE 1. Standard and Background Count Rates for $12 \mathrm{~g}$ Benzene

\begin{tabular}{|c|c|c|}
\hline Sample & Counts per minute $\pm 1 \sigma$ & $\delta^{13} \mathrm{C}(\% 0) \pm 1 \sigma$ \\
\hline \multicolumn{3}{|c|}{ Long and Kalin (1992) (old data - Quantulus no. 3) } \\
\hline Spec. benzene & $0.9244 \pm 0.0088$ & $-30.5 \pm 0.2$ \\
\hline $\begin{array}{l}\text { Calib } 83.2 \\
\text { (Anthracite) }\end{array}$ & Not counted & \\
\hline Calib 83.3 & $1.0375 \pm 0.0093$ & $-23.4 \pm 0.2$ \\
\hline (Anthracite) & & \\
\hline A-5883 & $1.0919 \pm 0.0095$ & $-21.1 \pm 0.2$ \\
\hline $\begin{array}{l}\text { Calib } 98 \\
\text { (ANU sucrose) }\end{array}$ & $157.2153 \pm 0.1145$ & $-10.2 \pm 0.2$ \\
\hline \multicolumn{3}{|c|}{ Long and Kalin (this study - Quantulus no. 4) } \\
\hline Spec. benzene & $1.2334 \pm 0.0101$ & $-30.5 \pm 0.2$ \\
\hline $\begin{array}{l}\text { Calib } 83.8 \\
\text { (Anthracite) }\end{array}$ & $1.5496 \pm 0.0227$ & $-23.8 \pm 0.2$ \\
\hline $\begin{array}{l}\text { Calib 83.6Á } \\
\text { (Anthracite) }\end{array}$ & $1.2772 \pm 0.0206$ & $-24.0 \pm 0.2$ \\
\hline $\begin{array}{l}\text { Calib 83.6B } \\
\text { (Anthracite) }\end{array}$ & $1.2544 \pm 0.0204$ & $-24.0 \pm 0.2$ \\
\hline $\begin{array}{l}\text { Calib } 83.7 \\
\text { (Anthracite) }\end{array}$ & $1.2614 \pm 0.0103$ & $-23.8 \pm 0.2$ \\
\hline $\begin{array}{l}\text { A-5883.3 } \\
\text { (Wood) }\end{array}$ & $1.4214 \pm 0.0109$ & $-20.5 \pm 0.2$ \\
\hline Calib 114 & $173.770 \pm 0.1204$ & $-10.6 \pm 0.2$ \\
\hline
\end{tabular}


for $12 \mathrm{~g}$ of benzene. The different values for background between the first and second runs reflect the two different Quantulus counters used for the two experiments. Figure 2 histograms illustrate the effect of run sequence in the same vacuum lines on the chemical blank. A sequence of anthracite samples showed a decreasing level of memory effect. Complete removal of memory effect requires two runs of anthracite. Figure 2A represents the first run on Péwé Sample 187, Figure 2B, the second. Figure $2 \mathrm{C}$ shows the memory effect resulting from a $10 \times$ modern sample, followed by anthracites. The "zero" level in all three figures is the background set by spectrophotometric benzene (Table 1).

Ages for samples run at routine precision in this laboratory are calculated using spectrophotometric benzene as the background. With $3 \mathrm{ml}$ of benzene counted for $2 \mathrm{k}$ min, differences in ${ }^{14} \mathrm{C}$ activity between spectrophotometric benzene and anthracite are statistically invisible. In the high-sensitivity mode, it is necessary to subtract the ${ }^{14} \mathrm{C}$ activity of the chemical blank from the sample count rate to correctly determine the ${ }^{14} \mathrm{C}$ activity of the wood sample. The best chemical blank would be a wood specimen known to be too old to contain measurable ${ }^{14} \mathrm{C}$, and which has been subjected to the same chemical and physical processing as the wood specimen of age to be determined. At the onset of this series of experiments, the white spruce specimen (Péwé no. 187) was thought to be such a chemical blank. Here we assume, until further experiments indicate otherwise, that this specimen represents our chemical blank. Thus, in high-sensitivity ${ }^{14} \mathrm{C}$ dating by LSC, we evidently have three levels of background/blank, listed in order of increasing ${ }^{14} \mathrm{C}$ activity: 1) spectroscopic benzene (not processed in laboratory); 2) anthracite-derived benzene (pretreated with inorganic solvents, then processed through laboratory); and 3) $>100$ ka cellulose (pretreated with organic solvent, then processed through laboratory).

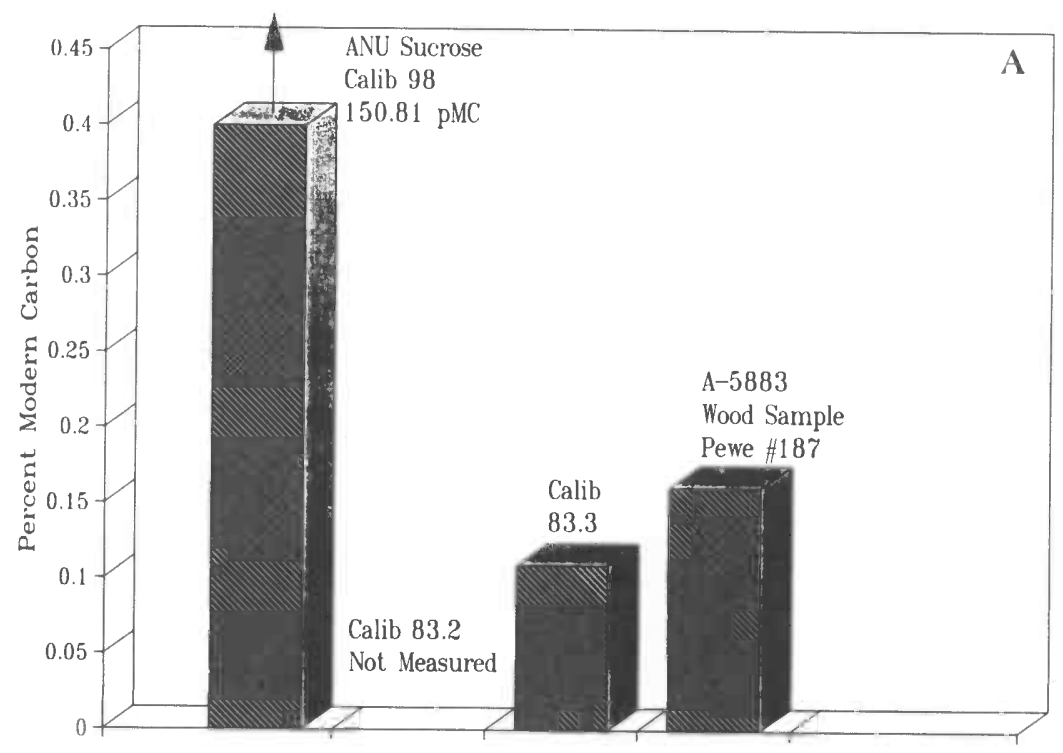

Order of Processing

Fig. 2. Histograms showing count rates of a series of standard, then anthracite samples preceding the two runs of the Eva Creek Spruce wood sample and a test with a sample containing enriched ${ }^{14} \mathrm{C}$. A. Memory effect of ANU sucrose in the combustion/benzene synthesis system for the 1990 series of runs. 


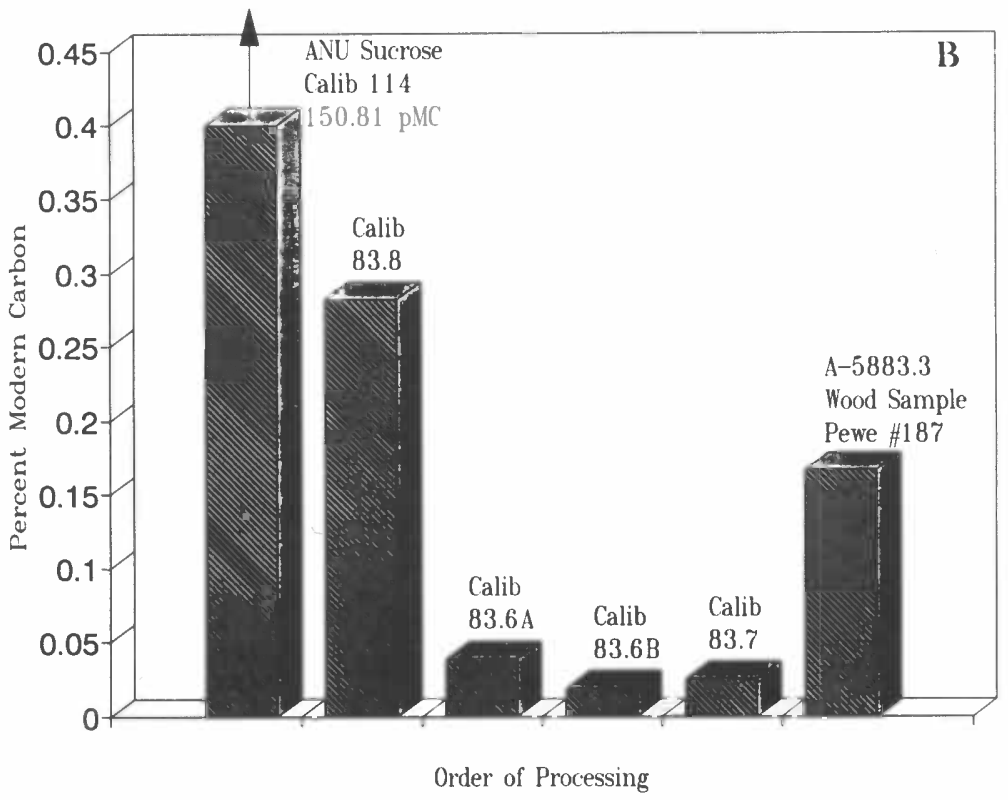

Fig. 2B. Memory effect of ANU sucrose in the combustion/benzene synthesis system for the 1992 series of runs.

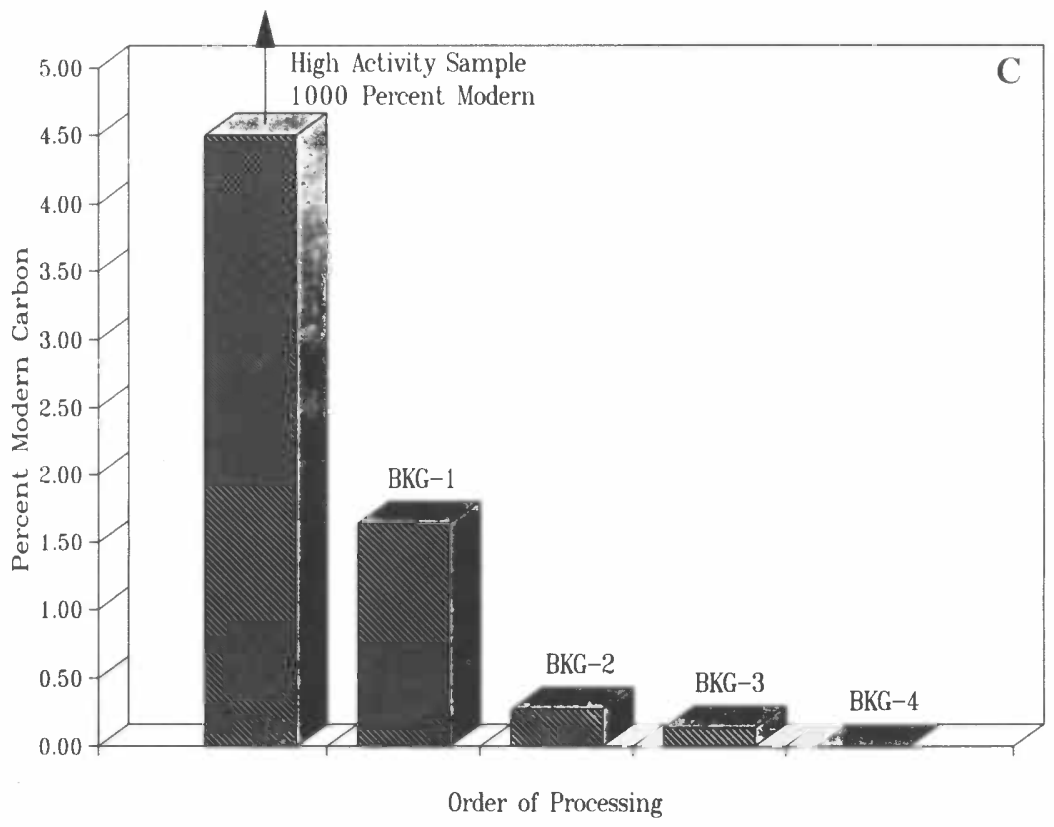

Fig. 2C. Memory effect resulting from a $10 \times$ modern sample (ANU isopropyl alcohol) followed by anthracite runs in the combustion/benzene synthesis system. Note scale difference. 


\section{Discussion}

The best estimate of the age of the wood specimen, based on its species and sedimentary position at time of collection, is $125 \mathrm{ka} \mathrm{BP}$. The fact that the calculated ${ }^{14} \mathrm{C}$ age for this wood specimen strongly disagrees with the stratigraphic age requires re-examination of the arguments leading to both age conclusions. Here, we focus only on the ${ }^{14} \mathrm{C}$ age obtained in this study. In-situ production of ${ }^{14} \mathrm{C}$ is considered highly unlikely to produce an apparent age this young (A. J. T. Jull, personal communication 1992).

Based on spectrophotometric benzene as the background, the calculated ages of the wood specimen from near Fairbanks, Alaska are 51,640 +790/-710 BP (first run, 1990, reported in Long \& Kalin 1992 ) and $51,230+790 /-710 \mathrm{BP}$ (second run, 1991, this study). Note that the two calculated ages are statistically indistinguishable. These dates show the reproducibility of high-sensitivity ${ }^{14} \mathrm{C}$ analyses in two different Quantulus counters separated by almost a year, but they cannot represent the age of the wood specimen, because spectrophotometric benzene is not a chemical blank at this level of sensitivity. Figure $2 \mathrm{~B}$ suggests that one anthracite following a sample of modern ${ }^{14} \mathrm{C}$ activity is insufficient to purge all remnants of ${ }^{14} \mathrm{C}$ from the system. A similar experiment, following ANU isopropyl alcohol with $10 \times$ modern ${ }^{14} \mathrm{C}$ activity run through the entire vacuum system (Fig. 2C) demonstrated that two purges are needed. This experiment further implies that reaction with surfaces of the lithium reaction vessel contributes significantly to the chemical blank.

Based on the average of the 3rd and 4th anthracites in Figure 2B as the chemical blank, the age calculated for Péwé no. 187 is $52,530+780 /-710$ BP. The calculated age actually published in Long and Kalin (1992) was $60,330+3120 /-2230 \mathrm{BP}$. This differs from the $52,530 \mathrm{BP}$ date, because the $60,330 \mathrm{BP}$ result is based on an erroneously high value for the anthracite chemical blank. If calculated based on the average of the $3 \mathrm{rd}$ and 4 th anthracite blanks in Figure $2 \mathrm{~B}$, the ${ }^{14} \mathrm{C}$ levels in the two analyses of the wood sample are statistically identical.

The remaining choice for chemical blank is the wood specimen, itself. If this turns out to be the correct blank, then the process of cellulose extraction contributes to the ${ }^{14} \mathrm{C}$ activity of the final benzene produced at the $52 \mathrm{ka}$ level, reproduced in two experiments separated by a year. The answer to the question of solvent-introduced ${ }^{14} \mathrm{C}$ blank awaits ${ }^{14} \mathrm{C}$ analysis of a $2 \mathrm{Ma}$ wood specimen, pretreated without organic solvents, now in process in our laboratory.

The calculated age based on spectrophotometric benzene as background is equivalent to 0.1862 pMC. Thus, a wood sample with $0.1862 \%$ contamination with modern carbon would have an apparent ${ }^{14} \mathrm{C}$ age of 51,420 BP (based on the conventional 5568 -yr half-life). Table 2 summarizes the possible sources of contaminant and the measures taken in this study to eliminate them.

Thus, the ${ }^{14} \mathrm{C}$ blank above the levels found in anthracite can be separated into 2 components: 1) chemical pretreatment - either non-removable substances from the soil, or remnants of solvents from laboratory processing; and 2) combustion/synthesis system. In these experiments, the chemical treatment component is the larger - ca. $15 \mathrm{mg}$ of modern carbon equivalent in the wood sample. The combustion/synthesis system contributed only slightly more than $2 \mathrm{mg}$ modern carbon equivalent.

Assuming that chemical pretreatment contamination is a solvable problem, either by elimination or by compensation, and that the variance of the chemical blank is comparable to that of counting statistics, the maximum determinable finite age, using this system and the $2 \sigma$ criterion, is $69 \mathrm{ka}$ conventional ${ }^{14} \mathrm{C}$ yr (71 ka, based on the 5730 -yr half-life). 
TABLE 2. Possible Sources of Contamination in Wood Specimen

\begin{tabular}{|c|c|c|}
\hline $\begin{array}{l}\text { Contaminant source in wood } \\
\text { specimen }\end{array}$ & $\begin{array}{l}\text { Laboratory procedure for } \\
\text { minimization }\end{array}$ & $\begin{array}{l}\text { Estimated contribution to } \\
\text { chemical blank }\end{array}$ \\
\hline Carbonate carbon in sediments & Acid treatment & None \\
\hline Organic carbon in sediments & $\begin{array}{l}\text { Extract cellulose fraction for } \\
\text { dating }\end{array}$ & $\begin{array}{l}\text { Unmeasurable; cellulose } \\
\text { rare in alluvial sediments }\end{array}$ \\
\hline $\begin{array}{l}\text { Microbiological growth in } \\
\text { wood }\end{array}$ & $\begin{array}{l}\text { Selected most solid segments } \\
\text { for processing }\end{array}$ & $\begin{array}{l}\text { Microscopic examination } \\
\text { yields no evidence. }\end{array}$ \\
\hline $\begin{array}{l}\text { Reagents in chemical treatment } \\
\text { procedure }\end{array}$ & $\begin{array}{l}\text { Only alcohol contains }{ }^{14} \mathrm{C} \text {; } \\
\text { sample boiled in water } \\
\text { to remove alcohol }\end{array}$ & $\begin{array}{l}\text { Possible, but unlikely; } \\
\text { ethanol not used in } \\
\text { anthracite preparation. }\end{array}$ \\
\hline $\begin{array}{l}\text { Combustion apparatus and } \\
\text { chemicals in acetylene prep. }\end{array}$ & $\begin{array}{l}\text { Present in all samples; } \\
\text { anthracite compensates }\end{array}$ & Estimate $0.005 \mathrm{cpm}$ \\
\hline $\begin{array}{l}\text { Apparatus and catalyst in ben- } \\
\text { zene preparation }\end{array}$ & $\begin{array}{l}\text { Present in all samples; } \\
\text { anthracite compensates }\end{array}$ & Unknown \\
\hline $\begin{array}{l}\text { Memory effect in counting } \\
\text { vials }\end{array}$ & $\begin{array}{l}\text { Thoroughly wash and dry } \\
\text { in vacuo }\end{array}$ & Unmeasurable \\
\hline Scintillant cocktail & $\begin{array}{l}\text { Present in all samples, } \\
\text { including spec. benzene }\end{array}$ & Estimate $0.006 \mathrm{cpm}$ \\
\hline
\end{tabular}

\section{SUMMARY, CONCLUSIONS AND FUTURE WORK}

Measurement of ${ }^{14} \mathrm{C}$ in natural materials has always required considerable care and attention to minute sources of contamination. Over the course of the maturation of the technique, the detection limit, in terms of maximum finite ages obtainable, has improved, from ca. $20 \mathrm{ka}$ with the original elemental carbon counters (Arnold \& Libby 1951; Anderson, Arnold \& Libby 1951), to gas proportional counters at $c a .55 \mathrm{ka}$ (Stuiver, Robinson \& Yang 1979), to isotopic enrichment - gas proportional counting (Grootes 1975) at $c a .75 \mathrm{ka}$. The present experiments suggest that if the inorganic pretreatment chemical blank is shown to be reproducible within counting statistics, LSC is capable of extended range ${ }^{14} \mathrm{C}$ dating to $c a .70 \mathrm{ka}$. Regardless of the ${ }^{14} \mathrm{C}$ detection technique employed, old samples are particularly susceptible to contaminant ${ }^{14} \mathrm{C}$ from the natural, precollection environment. Other sources of contamination are technique-dependent. The LSC process requires several more steps than gas proportional counting, but it does not require isotopic enrichment. With extreme care, the LSC technique should be able to extend the dating range to within one half-life of the current maximum limit of ${ }^{14} \mathrm{C}$ dating set by isotopic enrichment.

Tests are underway on more wood samples from Alaska and Canada, which are clearly associated with deposits even older than the one in this study. These samples have been pretreated without using organic solvents, and thus, will help resolve the question of ${ }^{14} \mathrm{C}$ blank.

\section{ACKNOWLEDGMENTS}

This research was supported by National Science Foundation grant BNS-8902140. We are grateful for the able technical help of Charles Tucek, Dai Kaimei, David Witkin and Steven van der Hoven. 


\section{REFERENCES}

Anderson, E. C., Arnold, J. R. and Libby, W. F. 1951 Measurement of low level radiocarbon. The Review of Scientific Instruments 22: 225-230.

Arnold, J. R. and Libby, W. F. 1951 Radiocarbon dates. Science 113: 111-120.

Grootes, P. M! 1977 Thermal Diffusion Isotopic Enrichment and Radiocarbon Dating Beyond 50,000 Years BP. Ph.D. Dissertation, University of Groningen: $221 \mathrm{p}$.

1978 Carbon-14 time scale extended: Comparison of chronologies. Science 200: 11-15.

Grootes, P. M., Mook, W. G., Vogel, J. C., de Vries, A. E., Haring, A. and Kistemaker, J. 1975 Enrichment of radiocarbon for radiocarbon dating of samples up to 75,000 years. Zeitschrift für Naturforschung. 30A: 1-14.

Grootes, P. M., Stuiver, M., Farwell, G. W., Schaad, T. P. and Schmidt, F. H. 1980 Enrichment of ${ }^{14} \mathrm{C}$ and sample preparation for beta and ion counting. Radiocarbon 22(2): 487-500.

Gupta, S. K. and Polach, H. A. 1985 Radiocarbon Dating Practices at ANU. Radiocarbon Laboratory, Research School of Pacific Studies, ANU, Canberra: $176 \mathrm{p}$.

Kalin, R. M. and Long, A. 1989 Radiocarbon dating with the Quantulus in an underground counting laboratory: performance and background sources. In Long, A. and Kra, R. S., eds., Proceedings of the 13th International ${ }^{14} \mathrm{C}$ Conference. Radiocarbon 31(3): 359-367.

Long, A. and Kalin, R. M. 1992 Radiocarbon dating in the 50,000 to 65,000 year range without isotopic enrichment. In Povinec, P., ed., Proceedings of the 14th Europhysics Conference on Nuclear Physics: Rare Nuclear Processes. Singapore, World Scientific: 256-263.
McCormac, F. G. 1992 Liquid scintillation counter characterization, optimization and benzene purity correction. Radiocarbon 34(1): 37-45.

Noakes, J. E., Isbell, A. F., Stipp, J. J. and Hood, D. W. 1963 Benzene synthesis by low temperature catalysis for radiocarbon dating. Geochimica et Cosmochimica Acta 27(7): 797-804.

Oeschger, H. and Wahlen, M. 1975 Low level counting techniques. Annual Review of Nuclear Science 25: 423-463.

Péwé, T. L. 1975 Quaternary stratigraphic nomenclature in central Alaska. U.S. Geological Survey Professional Paper 862: $32 \mathrm{p}$.

Polach, H. A. 1987 Evaluation and status of liquid scintillation counting for radiocarbon dating. Radiocarbon 29(1): 1-11.

Povinec, P. $1992{ }^{14} \mathrm{C}$ gas counting: Is there still a future? In Long, A. and Kra, R. S., eds., Proceedings of the 14th International ${ }^{14} \mathrm{C}$ Conference. Radiocar. bon, this issue.

Radnell, C. J. and Muller, A. B. 1980 Memory effects in the production of benzene for radiocarbon dating. In Stuiver, M. and Kra, R. S., eds., Proceedings of the 10 th International ${ }^{14} \mathrm{C}$ Conference. Radiocarbon 22(2): 479-486.

Stuiver, M. and Polach, H. A. 1977 Discussion: Reporting of ${ }^{14} \mathrm{C}$ data. Radiocarbon 19(3): 355-363.

Stuiver, M., Robinson, S. W. and Yang, I. C. $1979{ }^{14} \mathrm{C}$ dating to 60,000 years BP with proportional counters. In Berger, R. and Suess, H. E., eds., Radiocarbon Dating. Proceedings of the 9th International ${ }^{14} \mathrm{C}$ Conference. Los Angeles, University of California Press: 202-215.

Westgate, J. A. 1988 Isothermal plateau fission-track age of the late Pleistocene Old Crow tephra, Alaska. Geophysical Research Letters 15: 376-379. 